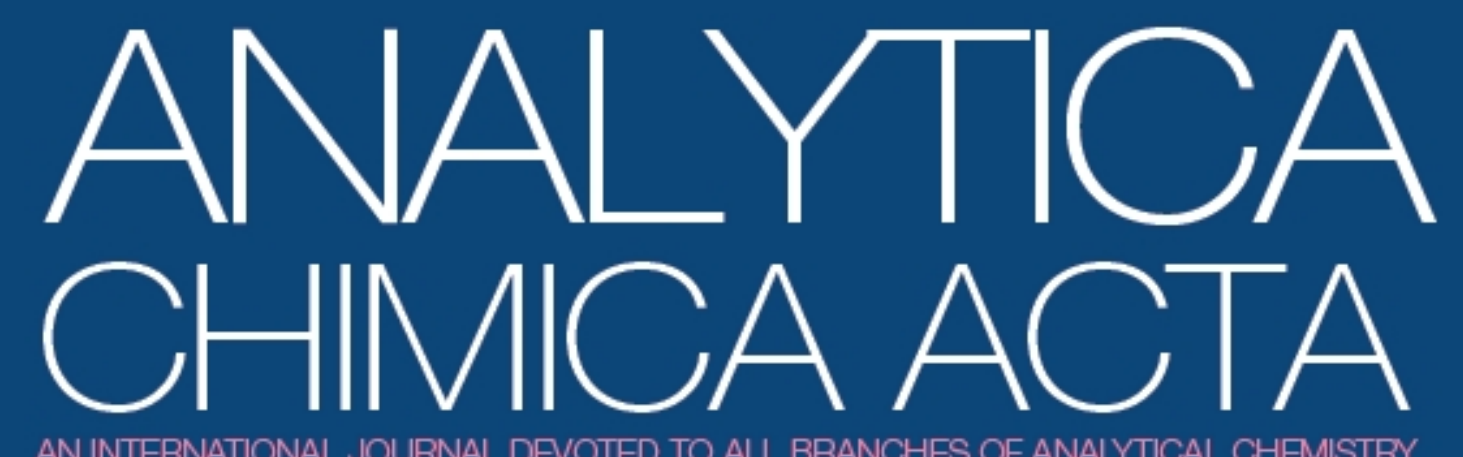

RICHARD P. BALDWIN Nel W. Barnett WOLFGANG BUCHBERGER LUTGARDE BUYDENS PURNENDU K. DASGUPTA ULRICH J. KRUL JAMES P. LANDERS LIANG LI JANUSZ PAWLISZYN

PAUL J. WORSFOLD

MANUE MIRó

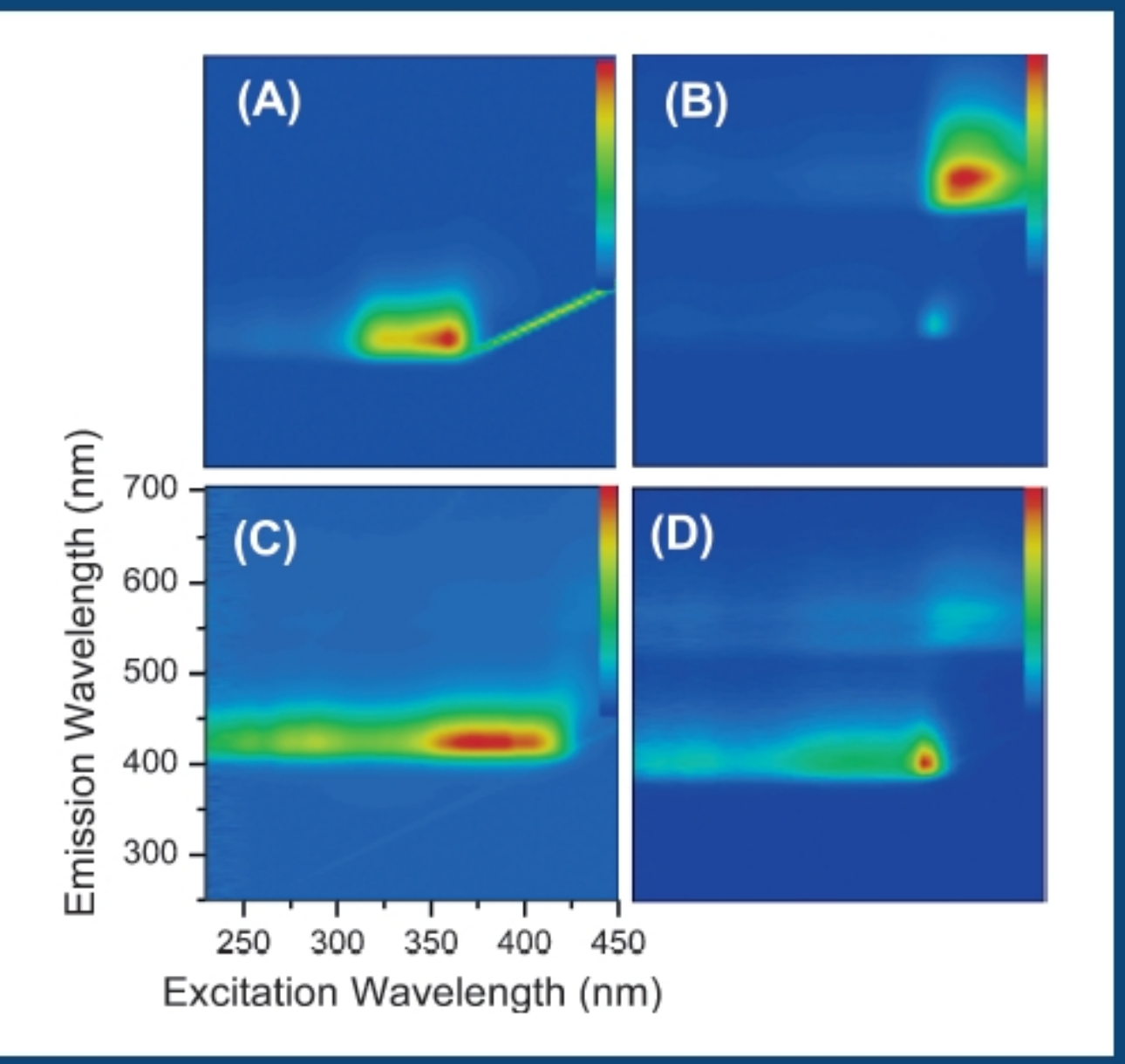

\section{Featured Article}

Assessment of the oxidative stability of lubricant oil using fibercoupled fluorescence excitation-emission matrix spectroscopy

Hengameh Omrani, Alexander E. Dudelzak, Bruce P. Hollebone and Hans-Peter Loock

(Published on pp. 1-12 of this issue) 
Provided for non-commercial research and education use. Not for reproduction, distribution or commercial use.

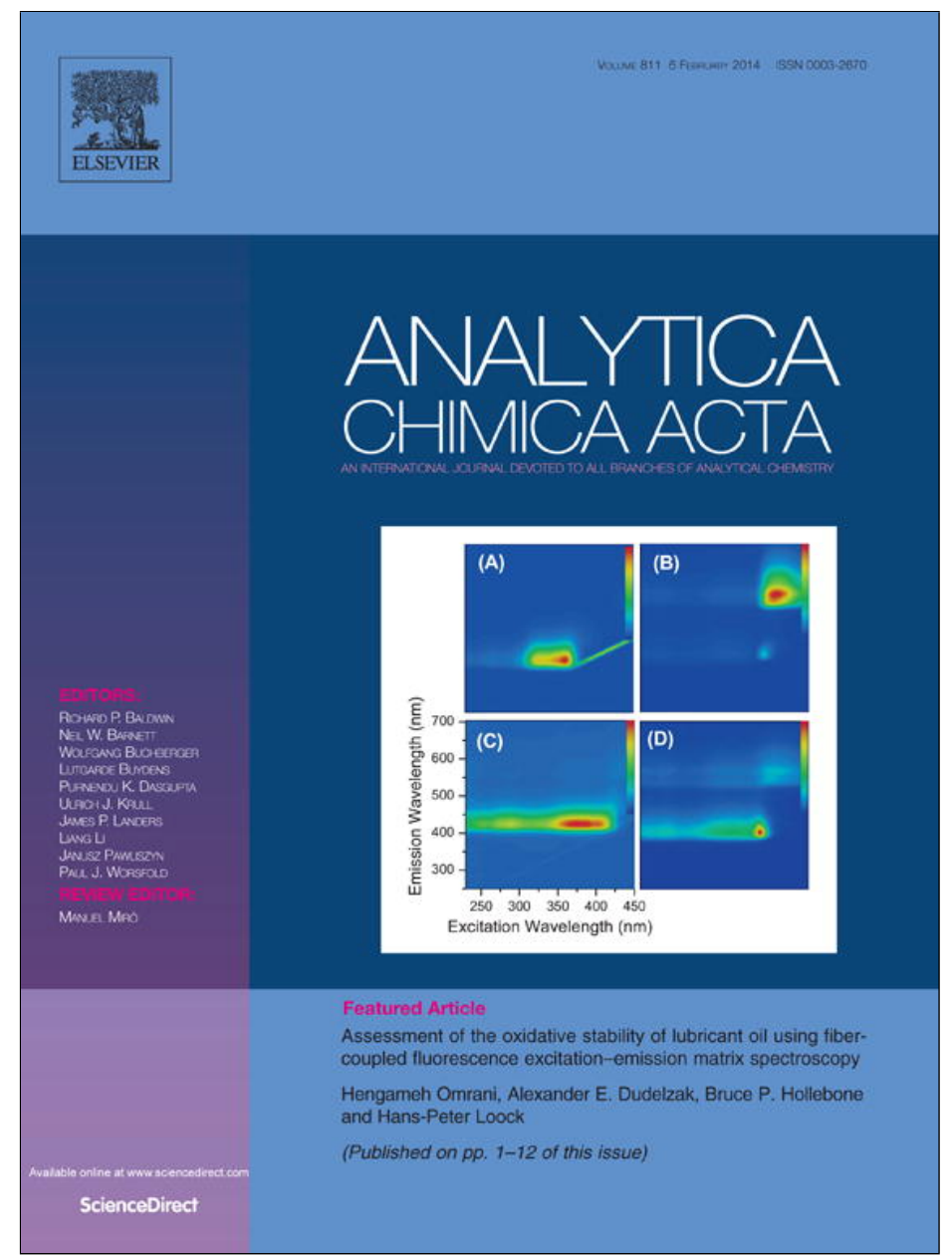

This article appeared in a journal published by Elsevier. The attached copy is furnished to the author for internal non-commercial research and education use, including for instruction at the authors institution and sharing with colleagues.

Other uses, including reproduction and distribution, or selling or licensing copies, or posting to personal, institutional or third party websites are prohibited.

In most cases authors are permitted to post their version of the article (e.g. in Word or Tex form) to their personal website or institutional repository. Authors requiring further information regarding Elsevier's archiving and manuscript policies are encouraged to visit:

http://www.elsevier.com/authorsrights 
Featured Article

\title{
Assessment of the oxidative stability of lubricant oil using fiber-coupled fluorescence excitation-emission matrix spectroscopy
}

\author{
Hengameh Omrani $^{\mathrm{a}, \mathrm{b}}$, Alexander E. Dudelzak ${ }^{\mathrm{a}, \mathrm{b}}$, Bruce P. Hollebone ${ }^{\mathrm{c}}$, \\ Hans-Peter Loock ${ }^{\mathrm{a}, *}$
}

a Department of Chemistry, Oueen's University, Kingston, ON, Canada K7L 3N6

b GasTOPS Ltd., 1011 Polytek Street, Ottawa, ON, Canada K1J 9J3

' Science E' Technology Branch, Environment Canada, 335 River Road, Ottawa, ON, Canada K1A OH3

\section{H I G H L I G H T S}

- A fiber-optic probe for engine lubricant quality has been designed.

- Fluorescence spectroscopy is used to monitor the concentration of antioxidants.

- A kinetic model for antioxidants degradation products was successfully developed.

- Fluorescence detection of antioxidants compares favorably to measurement of breakdown numbers.

\section{A R T I C L E I N F O}

Article history:

Received 1 August 2013

Received in revised form 9 October 2013

Accepted 10 October 2013

Available online 18 October 2013

\section{Keywords:}

Fluorescence spectroscopy

Lubricant

Oil

Fiber-optics

Kinetics

Chemometrics

\author{
G R A P H I C A L A B S T R A C T
}

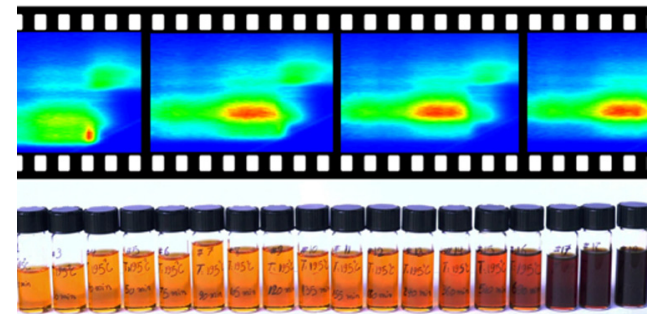

\begin{abstract}
A B S T R A C T
The fluorescence of antioxidant additives in lubricant oil was used as an indicator of oxidative stability of the oil. It was found that the decrease in fluorescence intensities of phenyl- $\alpha$-napthylamine, its dimer, and another unidentified antioxidant coincide with the formation of decomposition products of the oil base stock. Simple kinetic models were developed that were capable of describing antioxidant reactions as a pseudo first-order processes. It is shown that fluorescence excitation emission matrix (EEM) spectroscopy coupled with an optical fiber probe can provide real-time assessment of the oxidative stability of the lubricant. Parallel factor (PARAFAC) analysis was used to correlate the component scores to the oil breakdown number.
\end{abstract}

C 2013 Elsevier B.V. All rights reserved.

\section{Introduction}

Engine lubricants are used to reduce friction between the moving parts within an engine. Many engine lubricant oils also serve as coolants, corrosion protectors, and help remove contaminants and debris from the engine interior. By itself a lubricant oil, or "base stock", rarely has all the required properties and many additives

\footnotetext{
* Corresponding author. Tel.: +1 613533 2621; fax: +1 6135336669.

E-mail address: hploock@chem.queensu.ca (H.-P. Loock).
}

have been designed to improve the performance of the base stock-either by adding and enhancing properties of the base stock or by preventing changes in its composition. Lubricants age and degrade as the machine operates. This is due to oxidation as well as thermal and mechanical decomposition. Lubricant oils may then lose some of their functions, which may, in turn, lead to machine damage or even catastrophic failure. Lubricant oxidation is one of the leading causes of the degradation of hydrocarbon-based oils and can be influenced by several factors such as high engine temperature, the exposure to oxygen, water contamination and metallic wear debris, concentration and efficiency of antioxidants 
and other additives as well as the type of hydrocarbon-based oil itself [1]. Ultimately, oil oxidation leads to the formation of acidic compounds. Lubricant quality can therefore be characterized using the total acid number (TAN), which is obtained according to the ASTM guidelines [2]. Another common metric for lubricant quality is the so-called breakdown number (BDN), which is based on the mid-infrared absorption at around the $\mathrm{OH}$-stretch vibration wavenumber. The BDN is used frequently to describe ester-based lubricant oils such as the synthetic polyol esters in this study, which are commonly used as aviation and aerospace lubricants. The resulting polyol ester degradation products can be observed through their IR absorption features at $3595 \mathrm{~cm}^{-1}$ to $3500 \mathrm{~cm}^{-1}$, and $3325 \mathrm{~cm}^{-1}$ to $3150 \mathrm{~cm}^{-1}$, which are quoted, respectively, as breakdown number I and breakdown number II $[3,4]$. In addition, one can measure the oxidation stability of oils and fuels by a number of other methods [5-7].

The presence of antioxidant additives delays the oxidation of base stock either by reaction with oxygen or with primary oxidation products, such as organic radicals. The stable products of this reaction do not react further and thereby stop the radical chain reaction. Antioxidants therefore sacrificially protect the lubricant and are gradually consumed during this process. Once antioxidants are depleted, the oxidation of base stock will proceed as long as oxygen is allowed to interact with the liquid at high temperatures. For part of the base stock oxidation leads to larger oligomeric compounds and for other fractions it yields smaller oxidation products.

The Rancimat procedure measures the time it takes for volatile acids to evolve and is used in this study to characterize the oxidation stability of machinery fluids [8]. The method has been widely used for analyzing biodiesel fuels although its main application is the measurement of the oxidation stability of foodstuff. Here, an oil sample in a sealed vessel is heated while exposed to a flow of air. Once the antioxidants have been depleted, volatile organic acids are formed and are carried by the air stream into a vial of deionized water. The conductivity of the water in this vial is recorded continuously. After an induction time, which is proportional to the oxidation resistance (related to the concentration of antioxidants), a sharp increase in the water conductivity is found.

Since the useful lifetime of lubricant is determined by the concentration of remaining antioxidants, it appears more useful to monitor the antioxidant level and not the concentration of degradation products [9]. Monitoring antioxidants as proxy for lubricant quality has the additional advantage of a reduced occurrence of "false positive" warnings for low lubricant quality. Present methods that rely on the chemical or spectroscopic signatures of products will give false positives, whenever adequate oil is contaminated with oxidation products, but this may easily occur during an oil change when the engine interior has not been cleaned.

An additional concern with the accepted lubricant assessment methods lies in the required effort and expertise. All commonly accepted techniques used to determine lubricant oxidation require removal of a sample and off-line analysis. Even for large industrial machinery, a change of lubricants is therefore performed typically after a specified number of hours of operation (equivalent to the distance travelled in motor vehicles), but not when the lubricant has started to degrade.

We attempt to develop real-time and in-line methods and protocols to monitor the degradation of lubricant oils using fiber optic probes [10]. The ultimate goal of the work is development of a robust sensor and a continuous read-out system that contains a probe submersed permanently in the lubricant volume or flow. In this study, we use fluorescence excitation emission matrix (EEM) spectroscopy to characterize antioxidant performance as a polyol ester-based aviation lubricant oil is degraded by oxidation at elevated temperatures.
Fluorescence EEM produces three-dimensional spectra, i.e. a matrix of intensities that is obtained by recording fluorescence spectra at a variety of excitation wavelengths. The technique is now used in the analysis of different liquids in various fields from environmental [11,12] and bio-medical research [13] to foodstuff [14-16]. Fluorescence EEM has also been applied to petroleum products and other industrial liquids [17-20] and its many applications were reviewed recently [21-23]. Fiber-coupled EEM spectroscopy has already demonstrated potential for the identification and quantification of jet fuel and jet turbine oil and lends itself to in-line and real-time analysis. [10] In this previous article we showed that contamination of jet fuel with jet turbine oil can be detected and quantified between $10 \mathrm{ppm}$ and $1000 \mathrm{ppm}$ using a bifurcated fiber probe similar to that employed in the present study.

Fortunately, synthetic lubricant oils, such as the polyol esterbase stock used in this study, and also silicone oils, do not exhibit strong fluorescence when excited in the $220-450 \mathrm{~nm}$ region, whereas the polycyclic aromatic compounds that are added as antioxidants do fluoresce. It will be shown that the fluorescence signature of one of these antioxidants, phenyl- $\alpha$-naphtylamine (PAN), changes with time as the oil is heated and the PAN-dimer is formed as is apparent by the dimer's fluorescence EEM signature. The fluorescence of PAN, the PAN-dimer and another, unidentified antioxidant could be correlated to the established lubricant assessment methods such as the BDN measurements and the Rancimat procedure.

To investigate deterioration of the aviation lubricant oil, a laboratory bench simulation test has been developed. The lubricant oil was heated to temperatures that are typical for an aircraft turbine engine $\left(150-220^{\circ} \mathrm{C}\right)[24,25]$. We also collected oil samples, which have been degraded during aircraft engine operation. All lab and field samples were studied using fiber-coupled EEMS followed by chemometric data analysis using the parallel factor (PARAFAC) method.

\section{Materials and methods}

\subsection{Chemometric analysis}

EEM spectra contain quantitative analytical information, which is multidimensional in nature [26]. Several chemometric techniques are typically used for the necessary multivariate data analysis. Principal Component Analysis (PCA) and Regression (PCR) is one of the more popular chemometric methods because of its robustness and universality. Parallel Factor Analysis (PARAFAC) is another multi-way data decomposition model which can be applied to interpret the EEM data [27-30]. PARAFAC is less robust compared to PCA/PCR but has the advantage that the EEM signatures of the PARAFAC components can sometimes be related to chemical constituents, especially when a small number of distinct species contribute to a composite EEM spectrum as is the case in this study [31]. Stacking 2-dimensional EEM spectra from a series of samples creates a data cube that can be mathematically decomposed into a set of trilinear components and then modeled by PARAFAC in a matrix equation,

$X_{i j k}=\sum_{f=1}^{F} A_{i f} B_{j f} C_{k f}+E_{i j k}$

where $X_{i j k}$ is the fluorescence intensity of sample $k$ at the excitation wavelength $i$ and the emission wavelength $j . F$ is the number of unique spectral profiles ("components") found in the data cube. The columns of the $A, B$, and $C$ matrices are the estimates of the pure excitation, emission, and concentration profiles, respectively, 
and $E_{i j k}$ is the residual error matrix when the model has been fitted to the collected data. Details on PARAFAC analysis are given elsewhere $[27,29]$. Here, we performed a multi-way analysis of the 21 EEM spectra from jet turbine oil, which was oxidized in the lab, as well as of 56 EEM spectra of as many field samples, and 30 EEM spectra of a silicone-oil/PAN mixture, which was also aged in the lab. The PARAFAC model has been used together with principal components analysis and regression (PCA/PCR) to analyze the data. The latter method does no lend itself to a chemical decomposition of the sample, since the components are not related to chemical compounds, and will not be described here. The PARAFAC model was implemented with Matlab software (version 7.10.0) using the N-way toolbox [32] and using the DOMFluor toolbox [33] both provided by Bro.

\subsection{Sample preparation and fluorescence spectroscopy}

Commercially available jet turbine oil (NYCO, jet turbine oil, MIL-PRF-23699 F Class STD) was used in our oil degradation studies. The oil was based on polyol ester-base stock and had viscosity of $5 \mathrm{cSt}$ at $100^{\circ} \mathrm{C}$. Fresh and used oil samples were analyzed. Some of the lubricant samples were degraded in-house in a heated flask that was exposed to an airflow, whereas, other samples were obtained at oil change times from the main rotor engine (BCA Engine Turbo Shaft T58-GE) of a Sikorsky Sea King helicopter.

The lubricant oil degradation was studied by heating $800 \mathrm{~mL}$ of jet turbine oil at $195^{\circ} \mathrm{C}$ for $66 \mathrm{~h}$ in a $1 \mathrm{~L}$ round bottom flask using a thermostatically controlled silicone oil bath. The oil was subjected to airflow of $1.0 \mathrm{~L} \mathrm{~min}^{-1}$. Twenty-one samples of $30 \mathrm{~mL}$ each were taken according to a logarithmic time-scale plan.

The EEM spectra were measured using a spectrofluorometer (Varian, Cary Eclipse) in the "scan mode". The voltage of the built-in photomultiplier tube (PMT) fluorescence detector was set to $850 \mathrm{~V}$. A total of 46 scans were obtained at excitation wavelengths ranging from $230 \mathrm{~nm}$ to $450 \mathrm{~nm}$ with the $5 \mathrm{~nm}$ increment; each scan consisted of 550 emission wavelengths from $250 \mathrm{~nm}$ to $700 \mathrm{~nm}$ with the increment of $1 \mathrm{~nm}$. The bandwidths were $5 \mathrm{~nm}$ for both excitation and emission, and the scan rate was set at the $21 \mathrm{~nm} \mathrm{~s}^{-1}$ level, which resulted in 20 min of the data acquisition time for each of the two-dimensional EEM spectra. The sample preparation and analysis were then repeated for fresh oil samples heated to $150^{\circ} \mathrm{C}$ and $215^{\circ} \mathrm{C}$.

In preliminary experiments, fluorescence from two different cuvettes was collected at a $90^{\circ}$ angle to the xenon lamp excitation beam. The fiber bundle was prepared as described before $[10,34]$. In brief, six fibers $(400 / 440 \mu \mathrm{m})$ were used to illuminate the sample. Fluorescence was collected using 13 identical fibers. Scattering contributions were eliminated from all EEM spectra by manually discarding fluorescence measurements within $7 \mathrm{~nm}$ of the excitation wavelength, i.e. for which $\lambda_{\text {exc }}=\lambda_{\text {em }} \pm 7 \mathrm{~nm}$.

\subsection{Characterization of the fiber optic probe}

Lubricant oil can become opaque after a few hours of operation near $200^{\circ} \mathrm{C}$. The inner filter effect, i.e. absorption of the excitation light and reabsorption of fluorescence, can then severely restrict the dynamic range of spectroscopic measurements. For opaque samples, front-face fluorescence detection is most appropriate [34].

To characterize the influence of inner filter effects, fresh lubricant oil (MIL-PRF-23699) was analyzed-both neat and dissolved in hexane $\left(0.1 \%, 1000 \mathrm{ppm}_{\mathrm{v}}\right)$. The samples were placed in either a $10 \times 10 \mathrm{~mm}$ cuvette or in a $10 \times 1 \mathrm{~mm}$ cuvette, and fluorescence was collected at right angles.

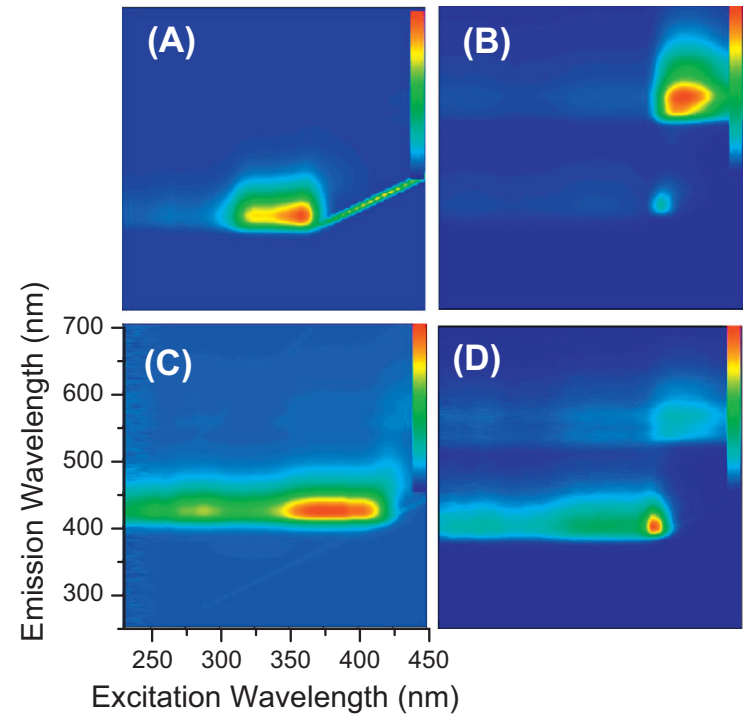

Fig. 1. EEM spectra of (A) fresh lubricant oil diluted in hexane, (B) neat oil in $10 \times 10 \mathrm{~mm}$ cuvette, (C) neat oil in $10 \times 1 \mathrm{~mm}$ cuvette, and (D) neat oil collected with bifurcated fiber probe. The axis labels refer to the wavelength scale of each individual EEM spectrum.

The spectra show two fluorescence EEM features, i.e. one emission peak at $400 \mathrm{~nm}$ associated with excitation around $360 \mathrm{~nm}$ $\left(360^{\mathrm{exc}} / 400^{\mathrm{em}} \mathrm{nm}\right)$, and a second feature around $420^{\mathrm{exc}} / 560^{\mathrm{em}} \mathrm{nm}$. The first feature is observable in diluted oil and in neat oil when the emission path is reduced to $1 \mathrm{~mm}$ but it is only faintly observable in the neat sample when using a $10 \times 10 \mathrm{~mm}$ cuvette. We attribute this observation to the reabsorption of the $400 \mathrm{~nm}$ emission by the neat oil.

On the other hand, the broad fluorescence band around $420^{\mathrm{exc}} / 560^{\mathrm{em}} \mathrm{nm}$ is apparent only in the neat oil and the cuvette having a long emission path (Fig. 1). It is caused by a weaker absorption at $420 \mathrm{~nm}$ and fluoresces in the wavelength range where oil is largely transparent. Since the $420^{\mathrm{exc}} / 560^{\mathrm{em}} \mathrm{nm}$ absorption and emission are rather weak, this fluorescence feature is neither visible in cuvettes with reduced emission path length nor in the diluted samples.

To address the fluorescence reabsorption issue (secondary absorption) we propose to collect fluorescence at the angles close to the excitation direction, i.e. near normal incidence. Strong absorption then causes fluorescence at short penetration depths, and presumably strong - fluorescence interacts with the sample only along this limited path. Weak absorption causes the sample to fluoresce in a much larger excitation volume. As a result, fluorescence will interact with the sample over a much longer reabsorption path. In the special, but common, case of samples exhibiting monotonically decaying absorption - from the UV to visible wavelengths the counter-propagating fluorescence is expected to compensate reabsorption significantly [34].

To enable in-line collection of EEM spectra, we have designed a bifurcated fiber bundle for collecting all the weak and strong fluorescence when the probe end is immersed in the sample volume. The spectrofluorometer was coupled to a bifurcated optical fiber bundle, which contains 19 multimode fibers (CeramOptec, core/cladding diameters of $400 / 440 \mu \mathrm{m}$ ); 6 of these fibers were used to deliver excitation light from the xenon lamp to the sample, and 13 fibers collected and guided the fluorescence emission from the sample to the dispersion element and the photomultiplier detector. In-line detection (submersing the fiber bundle in the heated oil) would therefore be possible. However, in the present article all experiments were made on samples that were withdrawn 


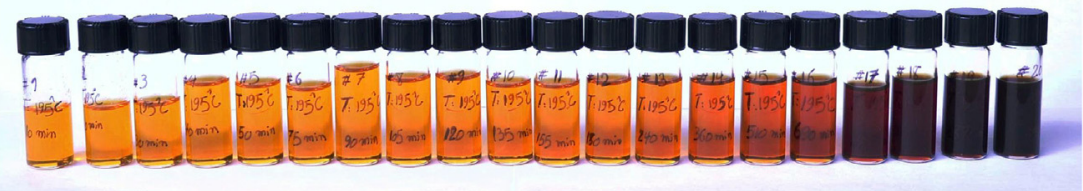

Fig. 2. Photo of samples taken at different times when oil was heated to $195^{\circ} \mathrm{C}$. From left: fresh turbine oil, and samples taken at the same intervals as described in Fig. 3 below.

from the pool, i.e. in an off-line fashion. We had to perform off-line analysis since we also had to measure FTIR absorption spectra to determine the oil breakdown numbers. In addition our EEM spectrometer takes up to $20 \mathrm{~min}$ to record a single EEM spectrum, which is longer than some of the sampling intervals.

Heating, taking samples and collecting EEMs of each sample were done at $150^{\circ} \mathrm{C}, 195^{\circ} \mathrm{C}$ and $215^{\circ} \mathrm{C}$. Fig. 2 show photographs of the samples taken at different time intervals after heating at $195^{\circ} \mathrm{C}$.

\section{Experimental results}

\subsection{Detection of the formation of volatile acids using the Rancimat method}

The Rancimat experiments on jet turbine oil were run at $150^{\circ} \mathrm{C}$, $195^{\circ} \mathrm{C}, 205^{\circ} \mathrm{C}$, and $215^{\circ} \mathrm{C}$. The Rancimat instrument (Metrohm 892) contains two heating units, which can be operated independently. Each unit has four channels.

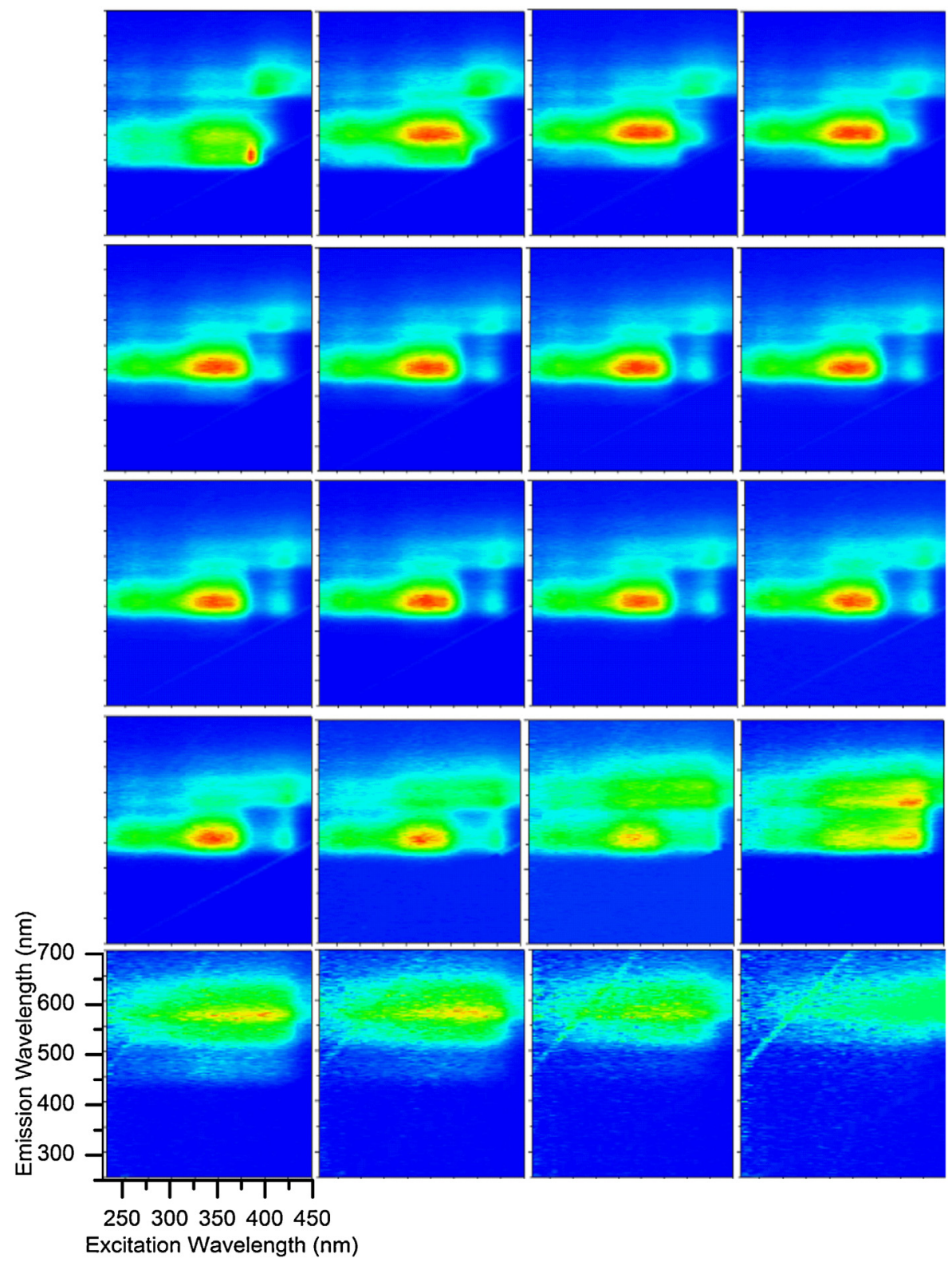

Fig. 3. EEM signatures of heated oil samples taken at different times, from left to right. First row: $10 \mathrm{~min}, 20 \mathrm{~min}, 30 \mathrm{~min}$ and $40 \mathrm{~min}$. Second row: $50 \mathrm{~min}$, $75 \mathrm{~min}, 90 \mathrm{~min}$ and $105 \mathrm{~min}$. Third row: $120 \mathrm{~min}, 135 \mathrm{~min}, 155 \mathrm{~min}$ and $180 \mathrm{~min}$. Forth row: $240 \mathrm{~min}, 360 \mathrm{~min}, 510 \mathrm{~min}$ and $690 \mathrm{~min}$. Fifth row: $1440 \mathrm{~min}, 2160 \mathrm{~min}, 2880 \mathrm{~min}$ and $3960 \mathrm{~min}$. 
Table 1

PARAFAC diagnostic parameters to assess the quality of the fit. Core consistency diagnostic (CORCONDIA) and the percentage of explained fit variation (RELFIT). Please see Ref. [35] for details.

\begin{tabular}{llll}
\hline CORCONDIA/RELFIT & 1 Component & 2 Components & 3 Components \\
\hline Aged oil in lab & $100 \% / 80.7 \%$ & $99.6 \% / 91.8 \%$ & $92.9 \% / 98.3 \%$ \\
Field samples & $100 \% / 85.5 \%$ & $96.7 \% / 91.2 \%$ & $89.4 \% / 98.3 \%$ \\
Si-oil/PAN & $100 \% / 83.0 \%$ & $99.4 \% / 98.2 \%$ & $85.0 \% / 98.6 \%$ \\
\hline
\end{tabular}

Before every run, all parts of the instrument were carefully cleaned to avoid contamination from previous experiments. For each temperature, the vessel containing $5 \mathrm{~mL}$ of oil was immersed into the heating unit only after the unit temperature became stable. The air stream (adjusted to $10 \mathrm{Lh}^{-1}$ ) was first bubbling through the oil and then through distilled water. The conductivity of the distilled water in the $60 \mathrm{~mL}$ vial was continuously recorded. To assure reproducibility, four experiments were run at each temperature simultaneously, either in four channels in the same unit $(4 \times 1)$, or in two channels in each of the two units $(2 \times 2)$. The differences between conductivity-time curves obtained at identical temperatures were found to be negligible.

\subsection{PARAFAC Analysis of jet turbine oil samples degraded in the} $l a b$

Fig. 3 shows 20 out of the total 21 fluorescence EEM spectra taken at different time intervals from the oil sample heated to $195^{\circ} \mathrm{C}$. We use the core consistency diagnostic (CORCONDIA) of the PARAFAC routines [35] to determine the optimal number of components and found that all $21 \mathrm{EEM}$ spectra can be fitted well using only 3 PARAFAC components (Table 1 ).

A continuous evolution of the EEM spectra is apparent and may be described by a rapid decrease of the initially strong peak at $370^{\mathrm{exc}} / 400^{\mathrm{em}} \mathrm{nm}$, an increase and decay of the feature at $400^{\mathrm{exc}} / 450^{\mathrm{em}} \mathrm{nm}$ and a more gradual decay of a weaker feature at $420^{\mathrm{exc}} / 580^{\mathrm{em}} \mathrm{nm}$. The EEM spectra of the three components are shown in Fig. 4 and their integrated excitation and emission spectra are shown in Fig. 5. Fig. 6 shows the change of the PARAFAC scores as the jet turbine oil is aged at three different temperatures. It is apparent that the scores of component 1 decreases with time while component 2 , presumably related to the primary oxidization process, increases. At about the same time that this primary reaction product decomposes we also observe the decay of the third

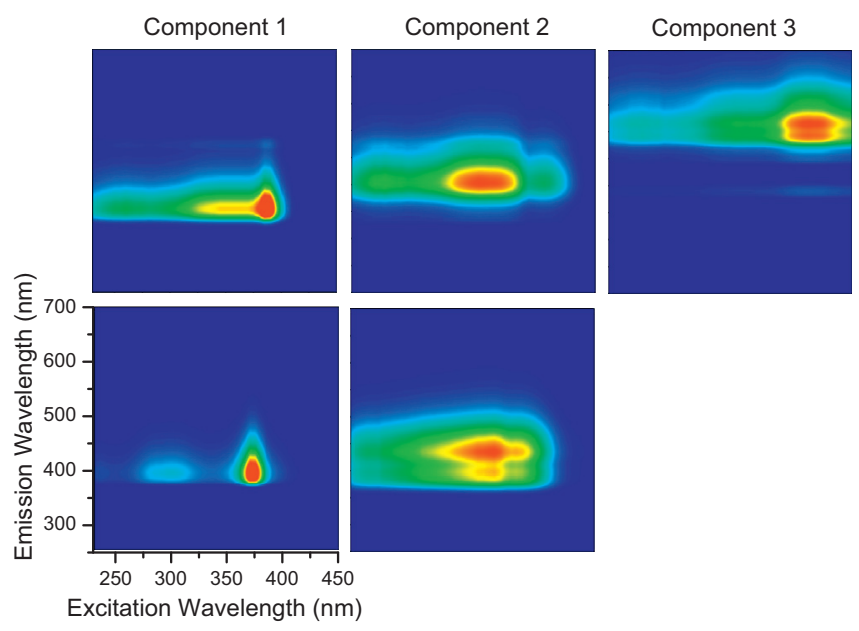

Fig. 4. Top row: EEM spectra of the three components associated with the PARAFAC decomposition of the spectra of 21 jet turbine oil samples that were aged at $195^{\circ} \mathrm{C}$ in the lab (shown in Fig. 3). The PARAFAC component spectra were then applied to the field-aged sample EEM spectra. Bottom row: PARAFAC components 1 and 2 obtained by analysis of the spectra of PAN in silicone oil at $195^{\circ} \mathrm{C}$ in the lab.
EEM component, which had until then not yet experienced a strong intensity change. The main fluorescence features of fresh oil can therefore be attributed to a sum of components 1 and 3 .

The experiments were repeated at $150^{\circ} \mathrm{C}, 195^{\circ} \mathrm{C}$ and $215^{\circ} \mathrm{C}$ and a separate PARAFAC analysis was carried out for each of the three data sets. The respective PARAFAC components at $T=150^{\circ} \mathrm{C}$, and $215^{\circ} \mathrm{C}$ were found to be very similar to those shown for $T=195^{\circ} \mathrm{C}$ in Figs. 4 and 5.

As is discussed below, we can attribute the three PARAFAC components to fluorescent antioxidants, where components 1 and 3 correspond to primary antioxidants that are used complementarily, while component 2 can be identified as a reaction product of oxygen with component 1 . Component 2 itself is not stable to oxidation and degrades to non-fluorescing products. To test this hypothesis we attempted a mass spectrometric analysis of fresh and degraded samples, but in the rather complex mixture present in commercial lubricant we were not able to identify any of the more common antioxidants, conclusively. Instead we rely on fluorescence analysis to identify component 1 as phenyl- $\alpha$-naphtylamine (PAN) and component 2 as the PAN dimer. This will be described in Sections 3.4 and 4.1 .
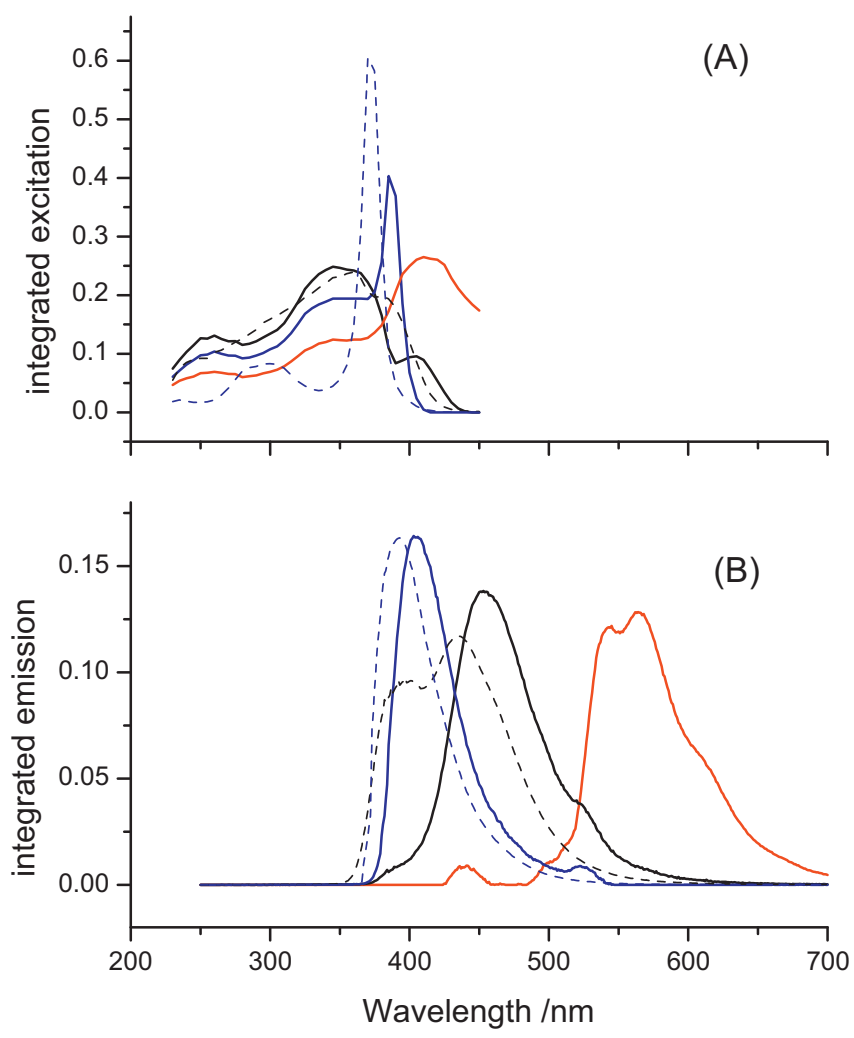

Fig. 5. (A) Excitation and (B) associated emission spectra of the three components from PARAFAC analysis (black: component 1, blue: component 2 and red: component 3 ). The solid lines are obtained from the PARAFAC analysis of the combined lab-aged samples and field samples, whereas the dashed lines were obtained by analysis of the aged samples of a PAN mixture in silicone oil.(For interpretation of the references to color in this figure legend, the reader is referred to the web version of this article.) 

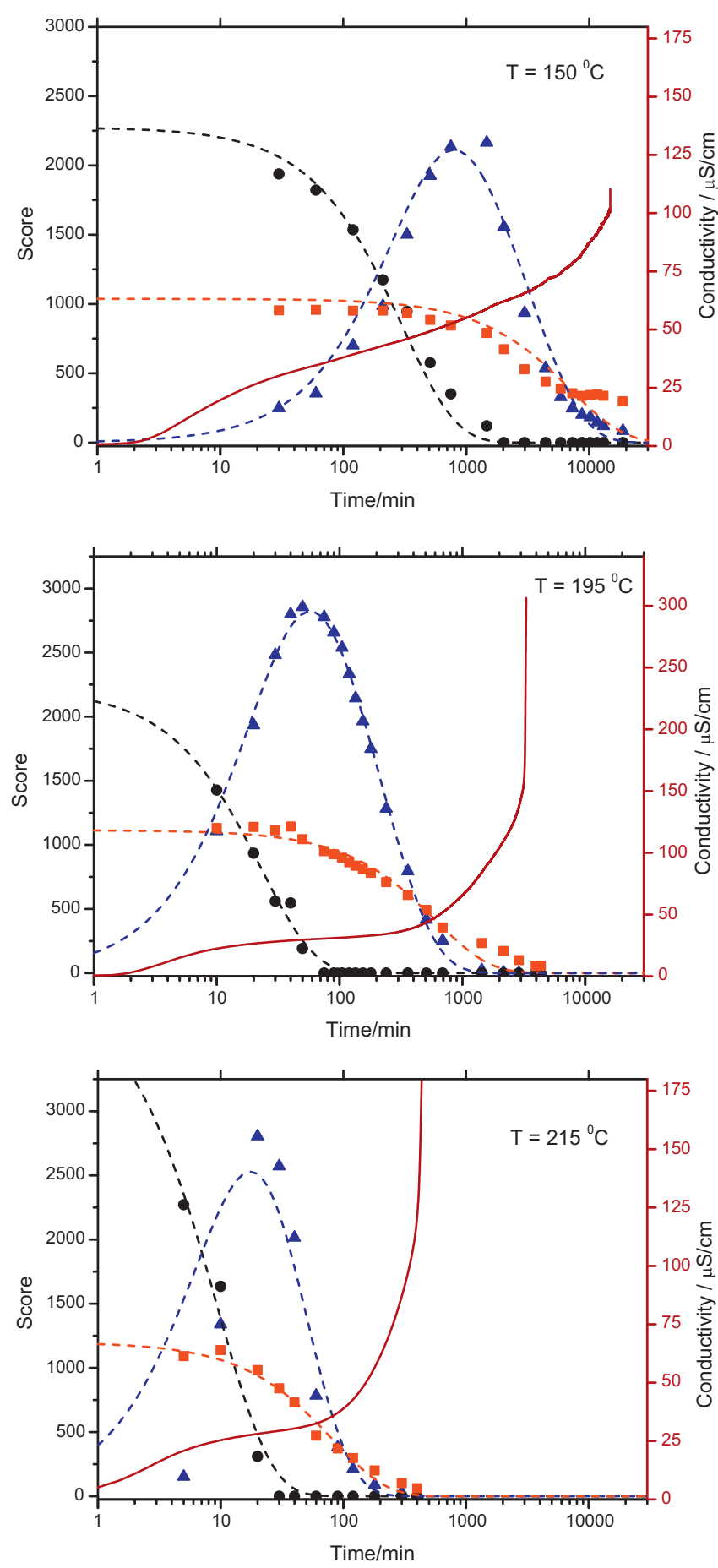

Fig. 6. Time evolution of the three PARAFAC components (black circles: component 1; blue triangles: component 2 and red squares: component 3 ) at three different temperatures as indicated. The dashed lines are obtained by fitting the data to the kinetic models describes in Section 4.2 and the solid brown line corresponds to the conductivity obtained independently using the Rancimat apparatus.(For interpretation of the references to color in this figure legend, the reader is referred to the web version of this article.)

One may suspect that the decrease in detected fluorescence intensity for all three components is caused by the greatly reduced attenuation length in the opaque ("black") used oil samples (see Fig. 2), instead of the decrease in fluorophore concentration.[34] To demonstrate that this "inner filter effect" is not responsible for the observed fluorescence decrease, we spiked a fresh oil sample and a heated oil sample $\left(3960 \mathrm{~min}\right.$ of heating at $195^{\circ} \mathrm{C}$ ) with $2000 \mathrm{ppm}_{\mathrm{V}}$ and $4000 \mathrm{ppm}_{\mathrm{V}}$ of the antioxidant PAN and recorded the respective increase in PARAFAC scores of component 1. In both cases we observe an increase of the score: by $0.21 \pm 0.05 \mathrm{scores} / \mathrm{ppm}_{\mathrm{V}}$ for the fresh oil and $0.28 \pm 0.05$ scores/ppm $\mathrm{pm}_{\mathrm{v}}$ for the heated oil. This shows that the reduced attenuation length is not responsible for the decrease in the PARAFAC scores, which is observed upon heating the oil. The decrease of detected fluorescence is then, indeed, due to a decreasing fluorophor concentration. The spiking experiment also lets us estimate the concentration of PAN in fresh oil as $0.6 \%$ to $0.8 \%$.

\subsection{PARAFAC analysis of jet turbine oil samples aged in jet engines}

Several jet turbine lubricant oil samples, collected at oil change time with different, and somewhat ill-specified, hours of operation were examined by EEM spectroscopy and interpreted using PARAFAC analysis. To determine the breakdown numbers FT-IR measurements at $3595 \mathrm{~cm}^{-1}$ to $3500 \mathrm{~cm}^{-1}$ were completed on all lab and field samples according to the ASTM protocol [6]. Determination of the breakdown number I (BDN-I) was performed in GasTOPS' laboratory.

As in Section 3.2 the PARAFAC core consistency diagnostic indicated that the data can be fit with only three components (Table 1 ). We therefore used only the lab samples from the previous section in our calibration set, while all field samples were placed in the prediction set. The PARAFAC analysis also showed that the relative scores of the three components changed with time (Fig. 7), however in contrast to Fig. 6 the correlation is rather weak. This was expected, since most samples were taken after a predetermined oil change time interval, when the lubricant had retained much if its function. The lubricants had therefore aged a similar and short amount of time in the engine. Of course, the oil samples that were oxidized for the specified period of time were not continuously operated at high temperature for the entire time. Also it is obvious that the scatter associated with the measurement of the scores is comparable to the change during the aging process. However a weak correlation is apparent: the concentration of component 1 decreased with time while that of component 2 increased. Component 3 has remained largely unchanged with PARAFAC scores

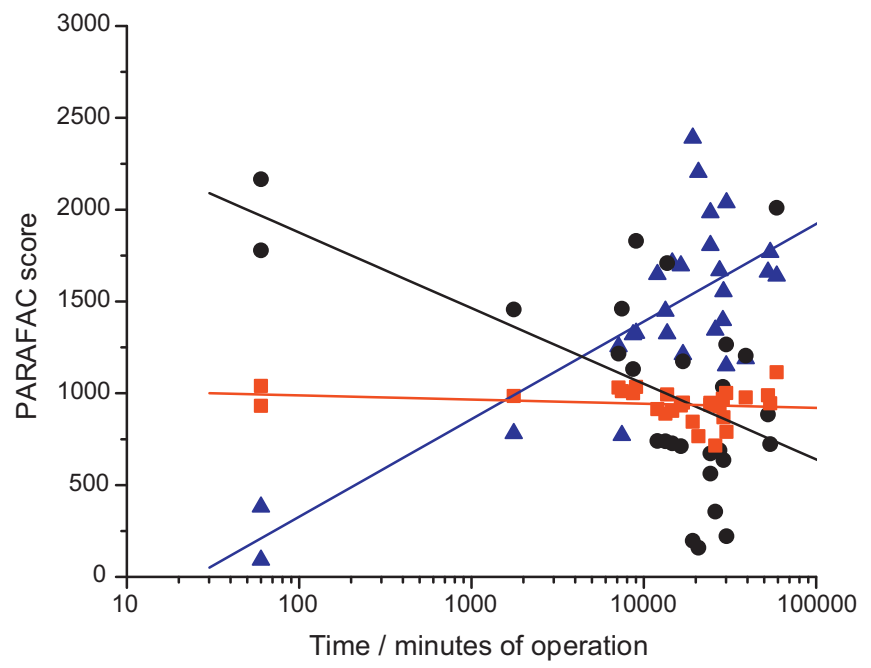

Fig. 7. Time evolution of the three PARAFAC components (black circles: component 1; blue triangles: component 2 and red squares: component 3 ) of the jet turbine oil when operated in an engine. The lubricant was collected at a time that corresponded to the oil change interval. The lines are linear fits to help guide the eye. (For interpretation of the references to color in this figure legend, the reader is referred to the web version of this article.) 


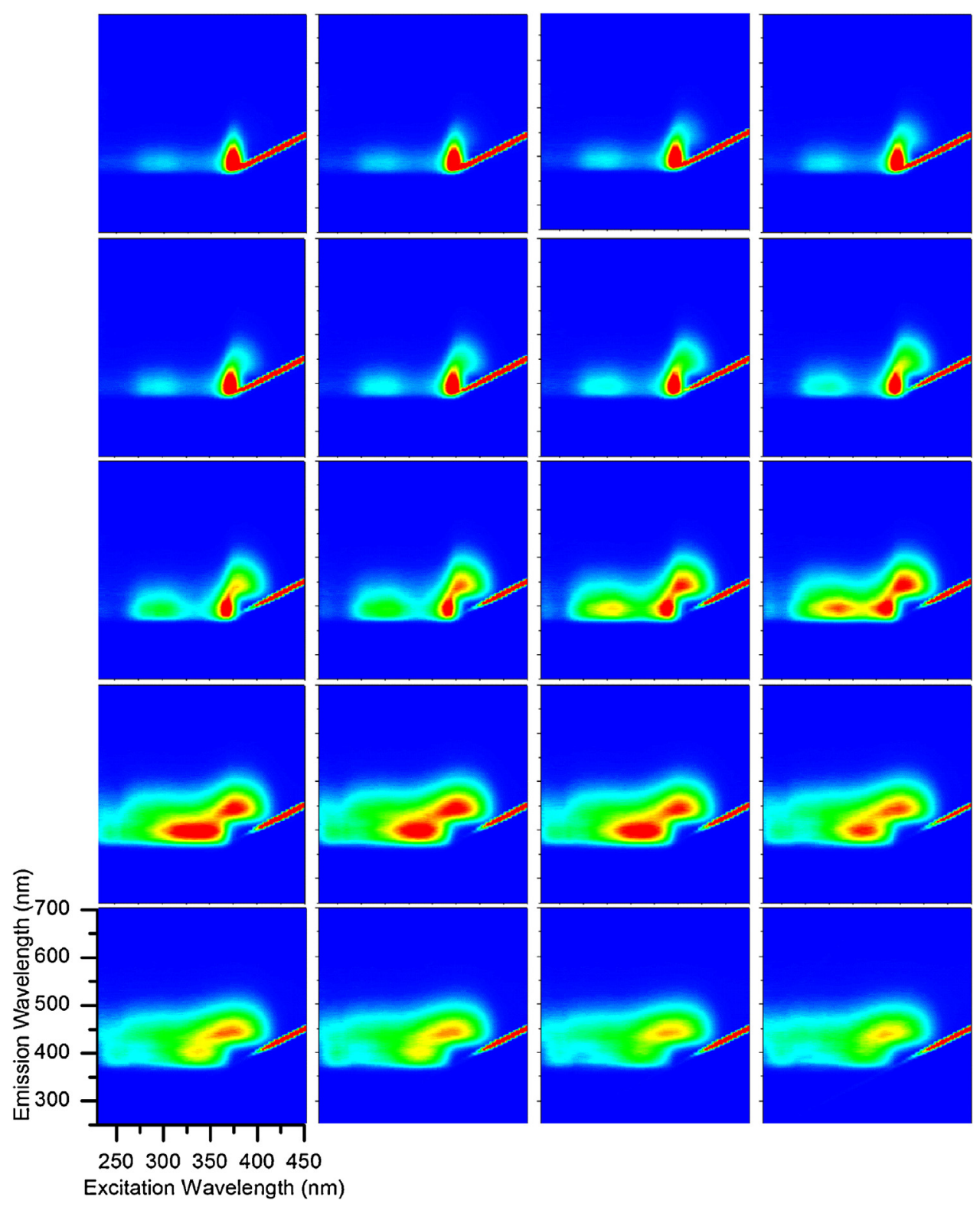

Fig. 8. Twenty out of the 30 EEM spectra of silicone oil and PAN ( $3.29 \mathrm{mmol} \mathrm{L}^{-1}$ or $623 \mathrm{ppm}_{\mathrm{v}}$ ) mixtures taken after different heating times. From left to right: First row: non heated, $50 \mathrm{~min}, 120 \mathrm{~min}$ and $155 \mathrm{~min}$. Second row: $180 \mathrm{~min}, 240 \mathrm{~min}, 360 \mathrm{~min}$ and $540 \mathrm{~min}$. Third row: $810 \mathrm{~min}, 1330 \mathrm{~min}, 1800 \mathrm{~min}$ and $2775 \mathrm{~min}$. Forth row: $5775 \mathrm{~min}$, $7695 \mathrm{~min}, 9015 \mathrm{~min}$ and 11,415 min. Fifth row: 13,035 $\mathrm{min}, 14,295 \mathrm{~min}, 16,275 \mathrm{~min}$ and 31,695 min.

between 600 and 1200, which is also shown in Fig. 10 below. The time evolution of the components in the field samples (Fig. 7) is therefore consistent with the behaviour of the lab samples shown in Fig. 6. The weakness of the correlation of PARAFAC scores to time of operation may simply indicate that the lubricant of the aircraft engine was changed before a significant chemical change in the lubricant occurred-as one would hope.

\subsection{PARAFAC analysis of silicone oil base stock containing PAN degraded in lab}

To test whether the fluorescence associated with component 1 could be attributed to phenyl- $\alpha$-naphtylamine (PAN) we prepared a synthetic "lubricant" consisting of silicone ( $\mathrm{Si}-$ ) oil and $3.29 \mathrm{mmol} \mathrm{L}^{-1}\left(623 \mathrm{ppm}_{\mathrm{V}}\right)$ PAN solutions. The Si-oil/PAN mixture was heated to $195^{\circ} \mathrm{C}$ and 30 samples were withdrawn at different times. The EEM spectra of the Si-oil/PAN (Fig. 8) can be described as a linear combination of only two component spectra (Fig. 4 and
Fig. 5b), which change in intensity as the mixture is heated (Fig. 9). The PARAFAC analysis indicated that the percentage of explained fit variation ("RELFIT", [35]) was larger than $98 \%$ with only two PARAFAC components and was not improved much when more components were added. This leads us to believe that component 1 can be attributed to PAN, and component 2 is produced in the reaction of PAN with oxygen. Interestingly, the core consistency values remained larger than $90 \%$ for up to five components. As was pointed out before [35] Rayleigh scattering may appear in the fluorescence EEM spectra as an extra component. On the other hand, the 3rd, 4th and 5th component may also be attributed to minor fluorescent reaction products that arise either from the oxidation of PAN or its primary oxidation product. In our analysis we used only two PARAFAC components in the fit. Similar to the jet turbine oil described in the previous sections, we did not observe fluorescence of base stock.

In contrast to the experiments on jet turbine oil the silicone oil base stock did not noticeably degrade or change colour. Since the 


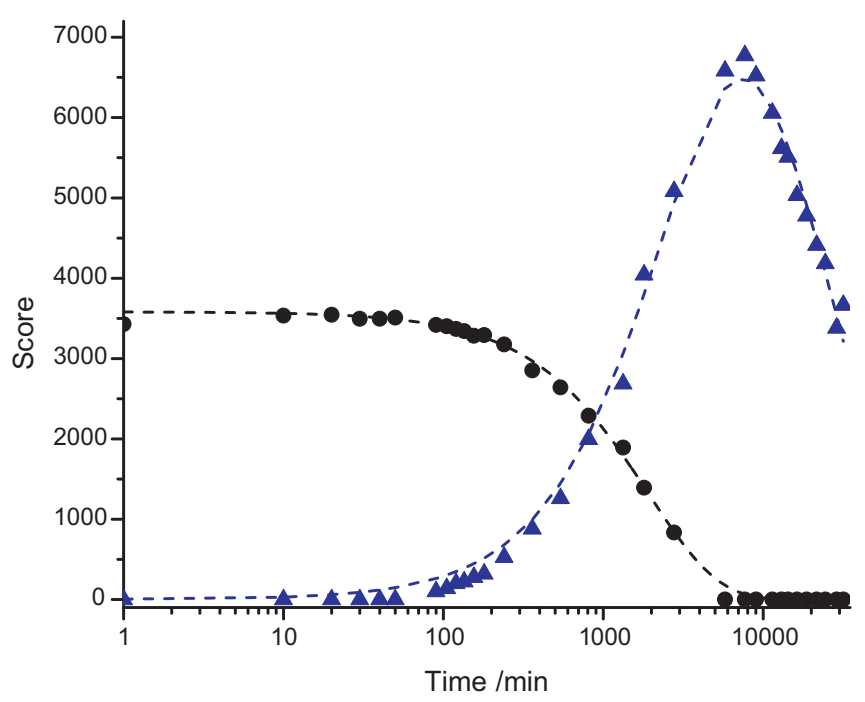

Fig. 9. Time evolution of the two PARAFAC components (black circles: component 1; blue triangles: component 2) of the mixture of PAN in silicone oil. The dashed lines are obtained by fitting the data to the kinetic models described in Section 4.2.(For interpretation of the references to color in this figure legend, the reader is referred to the web version of this article.)

detected fluorescence of both PARAFAC components nevertheless decreases, this decrease of fluorescence cannot be solely caused by inner filter effects, i.e. by absorption of excitation or fluorescence light. This lends further credibility to the correlation of decreased fluorescence with antioxidant concentration.

\subsection{Correlation of PARAFAC analysis to breakdown numbers}

As mentioned above we identified the EEM spectra of the PARAFAC component using the lab-heated samples (Fig. 4) and in the next step applied this calibration model to, both, the field samples and the lab samples, i.e. the same component spectra from lab samples were used on both data sets. Fig. 10 illustrates

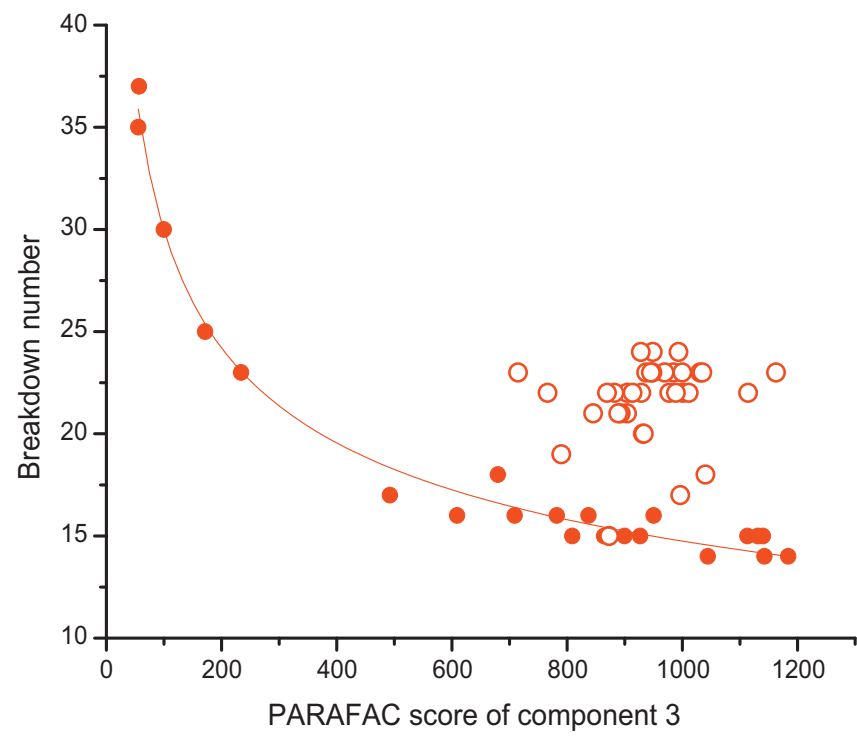

Fig. 10. The PARAFAC score of component 3 correlates well with the independently measured breakdown number when the oil is aged in the lab under controlled conditions (solid circles), but the correlation is worse when including the respective measurements of field samples (empty circles). The solid line is a fit to the simple function $\mathrm{BDN}=123 \times(\text { score })^{-0.3}$ and meant to be a guide to the eye. The lab samples with high BDN and low PARAFAC score correspond to those which have aged for the longest time. the correlation of scores of the third component of the oil that was aged in the lab and the breakdown number together with a simple, empirical non-linear fit function. It is apparent that the breakdown number of the calibration set could be predicted well using the fit equation in the caption of Fig. 10. While the samples that were aged in the lab show a monotonous trend and a strong correlation, the field samples do not follow this same correlation and show clustering. This indicates that they are approximately at the same, low, degradation level-as would be expected from the discussion in Section 3.3. We note that all field samples exhibit a BDN that is higher than may be expected from their time in the engine and from the PARAFAC component analysis. Since BDN are obtained by detecting oxidation products through their respective IR absorption, the field samples probably show contamination with very old lubricant that may have accumulated in the engine over a long time.

\section{Discussion}

\subsection{Lubricant oxidation chemistry}

As lubricants degrade their physical properties such as viscosity, hydrophobicity, and homogeneity change, thereby leading to increased friction and wear. This degradation is mainly due to oxidative degradation and thermal (non-oxidative) degradation. Thermal degradation occurs solely as a result of heat and mechanical forces, whereas oxidation is important in the presence of oxygen, especially when combined with heat and metal surfaces. The free radicals that are formed in the initial oxidation steps include alkyl, alkoxy and peroxy radicals. They further react with hydrocarbon molecules in the oil resulting in a chain reaction [36]. As end products one frequently finds carboxylic acids and longand short-chain hydrocarbons. Since the oxidation of oil propagates by free radical attacks against the base stock's compounds, radical scavengers can act as antioxidant additives. They interrupt the radical chain mechanism by donating hydrogen atoms to the hydrocarbon radicals and become stable radicals. Typically, blended polyol ester engine lubricants contain 1-3\% additives that are primarily antiwear and antioxidant additives. Antioxidant additives are usually aromatic compounds such as phenyl- $\alpha$-naphthylamine (PAN or PNA) or diphenylamine (DPA), as well as their derivatives such as octylphenyl- $\alpha$-naphthylamine (OPAN) and dioctyldiphenylamine (DODPA) [1]. Phosphate compounds may also be used to inhibit oxidation. Into blended polyol ester base stock one typically adds two or even more antioxidants that act in a synergistic relationship.

In the jet turbine lubricant used in this study one of these two antioxidants can be identified as PAN. As is apparent in the first panel of Fig. 8 the fluorescence of PAN in silicone oil shows a strong EEM feature at $370^{\mathrm{exc}} / 400^{\mathrm{em}} \mathrm{nm}$ which is also consistent with the EEM spectrum obtained in [37]. In addition, the EEM spectra of component 1 obtained from jet turbine oil and when mixing PAN into silicone oil (Fig. 4) are very similar to the EEM spectrum of the fresh Si-oil/PAN mixture (Fig. 8).

The second fluorescent additive (component 3 ) is more difficult to identify. For example, DPA exhibits fluorescence excitation and emission at shorter wavelengths than observed for PARAFAC component 3. This was confirmed, here, by recording the fluorescence EEM spectra of DPA in silicone oil $\left(320^{\mathrm{exc}} / 340^{\mathrm{em}} \mathrm{nm}\right.$; spectrum not shown). DODPA and DPA are expected to have similar fluorescence signatures, whereas OPAN should not exhibit a larger oxidative resistance compared to PAN. The mass spectrum of fresh jet turbine oil was also not conclusive, so we would rather not speculate on the identity of PARAFAC component 3.

On the other hand, PARAFAC component 2 is straightforward to identify as the PAN-dimer. When oxidizing silicone oil which 


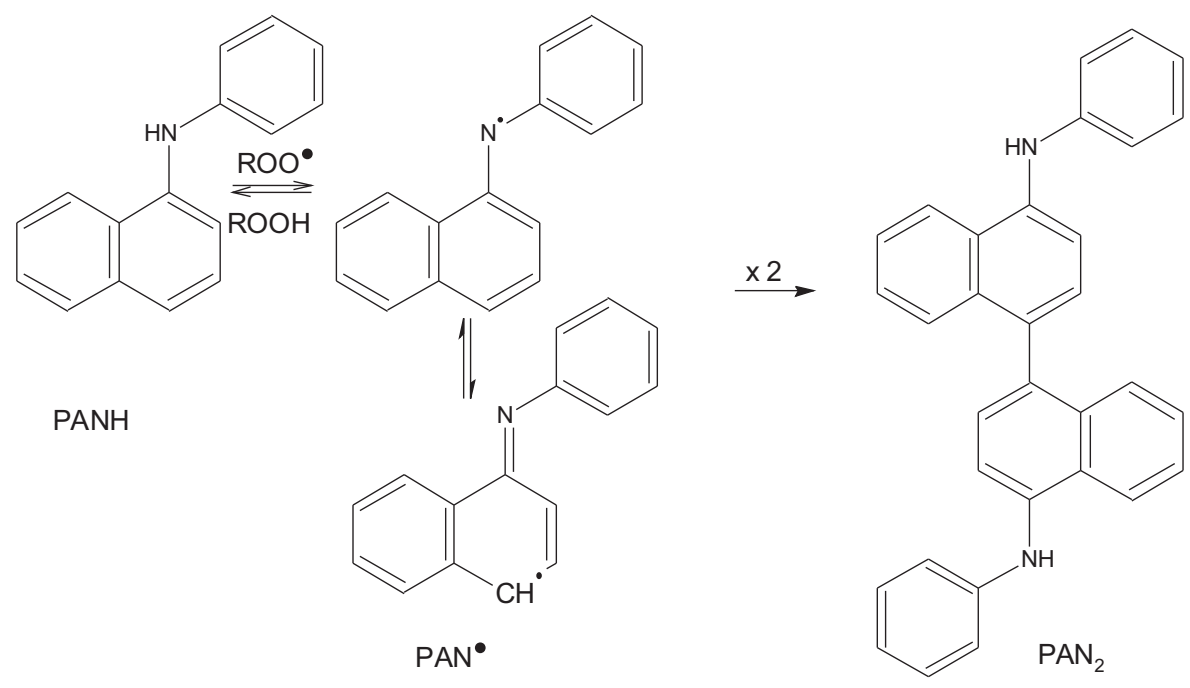

Scheme 1. Reaction of PANH with radicals and formation of the PAN-dimer.

contains PAN as its only antioxidant, the observed changes in the fluorescence EEM spectra are presumably due to the reaction of PAN with oxygen, rather than base stock radicals. It is known that PAN radicals form a dimer which can further act as an antioxidant (Scheme 1) [1].

In the following we designate unreacted phenyl- $\alpha$ naphthylamine as $\mathrm{PANH}$, the radical product as $\mathrm{PAN}^{\bullet}$ and the dimer as $\mathrm{PAN}_{2}$.

Our experimental results are consistent with the following simple model: PANH and PAN ${ }^{\bullet}$ are responsible for the strong fluorescence feature of component 1 which is apparent in fresh oil and, of course, in the mixture of PANH in silicone oil. The primary radical oxidation products or oxygen react with PANH to produce its dimer, $\mathrm{PAN}_{2}$, which we expect to exhibit absorption and fluorescence emission at slightly longer wavelengths than PAN. This was indeed observed for component 2. Once both PANH and $\mathrm{PAN}_{2}$ have been removed, oxidation modifies the remaining compounds which have higher oxidation stability. One of these is the unidentified antioxidant, $\mathrm{AO}$, which was detected as PARAFAC component 3. Apparently, the final oxidation products no longer strongly fluoresce and the PARAFAC scores of all three components decay eventually. Only when the antioxidants $\mathrm{AO}, \mathrm{PANH}$ and $\mathrm{PAN}_{2}$ have been depleted, the base-stock will be oxidized.

To test the hypothesis we performed mass spectrometric analysis of silicone oil containing initially just PANH as an antioxidant. Mass spectrometry revealed that a product with a mass to charge ratio of $437.2 \mathrm{amu}$ after $31,700 \mathrm{~min}$ of oxidation at $195^{\circ} \mathrm{C}$ was produced, in a process that is consistent with the formation of the $\mathrm{PAN}_{2}$ dimer from the PAN monomer.

In addition, we can associate the decrease in fluorescence, e.g. the depletion of antioxidants, with the onset of base oil oxidation. Fig. 6 shows that the conductivity of the water capturing the volatile reaction products of the lubricant oil oxidation increased as soon as the fluorescence of components 1-3 has diminished.

In combination these results permit us to specify the time at which the antioxidant additives are no longer capable of inhibiting oxidation of the base oil. In our case of forced and accelerated oxidation at high temperatures this point arrived at about $10,000 \mathrm{~min}$, $3500 \mathrm{~min}$ and $400 \mathrm{~min}$ when oil is heated to $150^{\circ} \mathrm{C}, 195^{\circ} \mathrm{C}$, and $215^{\circ} \mathrm{C}$, respectively. Importantly, this breakdown point can be obtained using a simple, submersible fiber probe.

When comparing the time evolution of the EEM spectra of field samples and lab samples it was found that the field samples had consistently high PARAFAC scores of component 3, whereas an FTIR analysis showed a much higher degree of oxidation (Fig. 10).
In the light of the above discussion, we note that (a) the oil change intervals are set such that the oil has sufficient lubricity, and antioxidants are therefore not depleted, (b) mixing of small amounts strongly oxidized oil (engine sludge) having a very high BDN-I with less strongly oxidized oil will show a strong oxidation signature in the FT-IR spectrum (high BDN-I), but may be still rich in antioxidants. It therefore appears as if the correlation between the BDN-I and the fluorescence EEM signature of component 3 (Fig. 10) is flawed, since the BDN-I represents the amount of oxidation products and the fluorescence measurement represents the amount of anti-oxidants. Since it is more important to know the antioxidant level and therefore the oxidation resistance of the base-oil than to know the level of contamination with heavily oxidized species, we submit that the fluorescence EEM signatures are more reliable indicators for oil lubricity, than conventionally obtained breakdown numbers. Importantly, the fluorescence measurements of the field samples are just as accurate as those of the lab samples and the origin of the scatter in Figs. 7 and 10 lies in the BDN-I measurements.

\subsection{Kinetic model}

We consider a greatly simplified model for the reaction of inhibitors PANH and AO with organic radicals, (R, RO, and the peroxy-radicals ROO) that are formed either by oxidation or pyrolysis $[25,38]$.

$$
\begin{aligned}
& \mathrm{RH}+\mathrm{O}_{2} \rightarrow \mathrm{R}^{\bullet}+\mathrm{HO}_{2}^{\bullet} \\
& \mathrm{R}^{\bullet}+\mathrm{O}_{2} \rightarrow \mathrm{ROO}^{\bullet} \\
& \mathrm{ROO}^{\bullet}+\mathrm{RH} \rightarrow \mathrm{R}^{\bullet}+\mathrm{ROOH} \\
& \mathrm{HO}_{2}^{\bullet}+\mathrm{RH} \rightarrow \mathrm{H}_{2} \mathrm{O}_{2}+\mathrm{R}^{\bullet} \\
& \mathrm{ROOH} \rightarrow \mathrm{OH}^{\bullet}+\mathrm{RO}^{\bullet}\left(\mathrm{RR}^{\prime} \mathrm{HCO}^{\bullet}, \mathrm{RR}^{\prime} \mathrm{R}^{\prime \prime} \mathrm{CO}^{\bullet}\right) \\
& \mathrm{RO}^{\bullet}+\mathrm{RH} \rightarrow \mathrm{ROH}+\mathrm{R}^{\bullet} \\
& \mathrm{HO}^{\bullet}+\mathrm{RH} \rightarrow \mathrm{H}_{2} \mathrm{O}+\mathrm{R}^{\bullet}
\end{aligned}
$$

The oxyradical RO can be primary, secondary, or tertiary depending on the position of the initial $\mathrm{CH}$ bond cleavage. Secondary and tertiary oxyradicals have the potential to further decompose to give aldehydes and ketones, respectively.

$\mathrm{RR}^{\prime} \mathrm{HCO}^{\bullet} \rightarrow \mathrm{R}^{\prime} \mathrm{CHO}+\mathrm{R}^{\bullet}$

$\mathrm{RR}^{\prime} \mathrm{R}^{\prime \prime} \mathrm{CO} \rightarrow \mathrm{R}^{\prime} \mathrm{R}^{\prime \prime} \mathrm{CO}+\mathrm{R}^{\bullet}$ 
In the absence of inhibitors or antioxidants the oxidation proceeds to give volatile organic acids $\mathrm{RCOOH}$, which can be detected by solvation in water and conductivity measurements.

$$
\begin{aligned}
& \mathrm{R}^{\prime} \mathrm{CHO} . \stackrel{+\mathrm{ROO} \cdot\left(\mathrm{O}_{2}\right) \cdot}{\underset{\mathrm{ROOH}}{\longrightarrow}} \mathrm{R}^{\prime} \mathrm{COOH} \\
& \mathrm{RR}^{\prime} \mathrm{CO} . \stackrel{+\mathrm{ROO}\left(\mathrm{O}_{2}\right) \cdot}{\stackrel{+\mathrm{ROOH}}{\longrightarrow}} \mathrm{RCHO}+\mathrm{R}^{\prime} \mathrm{COOH}
\end{aligned}
$$

In the presence of antioxidants such as PANH the radicals are scavenged and converted into stable compounds

$\mathrm{PANH}+\mathrm{R}^{\bullet} \stackrel{k_{1}}{\longrightarrow} \mathrm{PAN}^{\bullet}+\mathrm{RH}$ where $\mathrm{R}=\mathrm{R}, \quad \mathrm{RO}, \quad \mathrm{RCO}_{2}$, etc.

$2 \mathrm{PAN}^{\bullet} \stackrel{k_{2}}{\longrightarrow} \mathrm{PAN}_{2}$

$\mathrm{PAN}_{2}+\mathrm{R} \cdot \stackrel{k_{3}}{\longrightarrow}($ Product $)+\mathrm{RH}$

$\mathrm{AO}+\mathrm{R}^{\bullet} \stackrel{k_{4}}{\longrightarrow}($ Product $)+\mathrm{RH}$

The concentration-time profiles of the fluorescent molecules $\mathrm{PANH}$ and $\mathrm{PAN}_{2}$ as well as the antioxidant molecule AO are therefore determined by the rate equations

$$
\begin{aligned}
& \frac{d[\mathrm{PANH}]}{d t}=-k_{1}[\mathrm{PANH}]\left[\mathrm{R}^{\bullet}\right] \\
& \frac{d\left[\mathrm{PAN}^{\bullet}\right]}{d t}=k_{1}[\mathrm{PANH}]\left[\mathrm{R}^{\bullet}\right]-k_{2}\left[\mathrm{PAN}^{\bullet}\right]^{2} \\
& \frac{d\left[\mathrm{PAN}_{2}\right]}{d t}=k_{2}\left[\mathrm{PAN}^{\bullet}\right]^{2}-k_{3}\left[\mathrm{PAN}_{2}\right]\left[R^{\bullet}\right] \\
& \frac{d[\mathrm{AO}]}{d t}=-k_{4}[\mathrm{AO}]\left[\mathrm{R}^{\bullet}\right]
\end{aligned}
$$

One may make the following assumptions:

(1) The consumption rate of the fluorescent antioxidant molecule(s) AO is slower than that of PANH: $k_{4}<k_{1}$

(2) The concentration of PAN-radicals is constant, while PANH is at large excess over the organic radicals $\left[\mathrm{R}^{\bullet}\right]$. This allows setting $k_{1}[\mathrm{PANH}]\left[\mathrm{R}^{\bullet}\right]=k_{2}\left[\mathrm{PAN}^{\bullet}\right]^{2}$

(3) The concentration of organic radicals, [ $\left.R^{\bullet}\right]$, is constant while PANH is at large excess over these radicals. This allows setting $k_{1}^{\prime}=k_{1}\left[\mathrm{R}^{\bullet}\right], \quad k_{3}^{\prime}=k_{3}\left[\mathrm{R}^{\bullet}\right], \quad k_{4}^{\prime}=k_{4}\left[\mathrm{R}^{\bullet}\right]$.

With these assumptions we can rewrite Eq. (3) as

$\frac{d\left[\mathrm{PAN}_{2}\right]}{d t}=k_{1}^{\prime}[\mathrm{PANH}]-k_{3}^{\prime}\left[\mathrm{PAN}_{2}\right]$

Solving the differential equations gives

$[\mathrm{PANH}]=[\mathrm{PANH}]_{0} \exp \left(-k_{1}^{\prime} t\right)$

$\left[\mathrm{PAN}_{2}\right](t)=\frac{k_{1}^{\prime}[\mathrm{PANH}]_{0}}{k_{3}^{\prime}-k_{1}^{\prime}}\left\{\exp \left(-k_{1}^{\prime} t\right)-\exp \left(-k_{3}^{\prime} t\right)\right\}$

$[\mathrm{AO}]=[\mathrm{AO}]_{0} \exp \left(-k_{4}^{\prime} t\right)$

Eq. (7) was derived from Eqs. (5) and (6)

$\frac{d\left[\mathrm{PAN}_{2}\right]}{d t}+k_{3}^{\prime}\left[\mathrm{PAN}_{2}\right]=k_{1}^{\prime}[\mathrm{PANH}]=k_{1}^{\prime}[\mathrm{PANH}]_{0} \exp \left(-k_{1}^{\prime} t\right)$

Eq. (9) is an inhomogeneous differential equation for [PAN $\left.{ }_{2}\right]$ The general solution is the sum of two terms, i.e. the solution to the homogeneous equation, with the RHS equal to zero, and the
Table 2

Rate constants for the formation of $\mathrm{PAN}_{2}$ and the decay of PANH, $\mathrm{PAN}_{2}$ and $\mathrm{AO}$ in jet turbine oil obtained by fitting rate Eqs. (6)-(8) to the data in Fig.6 and activation energies to data of Fig. 11. The two values of $[\mathrm{PANH}]_{0}$ are obtained from two separate fits to Eqs. (6) and (7).

\begin{tabular}{lllll}
\hline$T(\mathrm{~K})$ & 423 & 468 & 488 & $E_{a}\left(\mathrm{~kJ} \mathrm{~mol}^{-1}\right)$ \\
\hline$[\mathrm{PANH}]_{0}$ & $2275 / 2697$ & $2215 / 3694$ & $4097 / 4097$ & \\
$k^{\prime}{ }_{1}\left(\mathrm{~min}^{-1}\right)$ & 0.003296 & 0.043358 & 0.10882 & $93 \pm 2$ \\
$k^{\prime}{ }^{3}\left(\mathrm{~min}^{-1}\right)$ & 0.00030929 & 0.0046778 & 0.027064 & $114 \pm 15$ \\
$k^{\prime}{ }_{4}\left(\mathrm{~min}^{2}\right.$ & 0.000121 & 0.001652 & 0.012456 & $116 \pm 20$ \\
\hline
\end{tabular}

particular solution for the equation with the non-zero RHS. The homogeneous solution is

$\left[\mathrm{PAN}_{2}\right](t)=A \exp \left(-k_{3}^{\prime} t\right)$

while the particular solution is

$\left[\mathrm{PAN}_{2}\right](t)=-A \exp \left(-k_{1}^{\prime} t\right)$

Requiring that $\left[\mathrm{PAN}_{2}\right](t=0)=0$ defines $A=-k_{1}^{\prime}[\mathrm{PANH}]_{0} / k_{3}^{\prime}-$ $k_{1}^{\prime}$, and the general solution is therefore given by Eq. (7).

Despite the simplicity and crudeness of this model, the fluorescence time profiles can be described very well over an astonishing three temporal orders of magnitude, i.e. from about $10 \mathrm{~min}$ to 10,000 min. From a fit to Eqs. (6)-(8) to the fluorescence-time profiles (Fig. 6 and Fig. 9) we were able to determine rate constants $k_{1}^{\prime}$, $k_{3}^{\prime}$ and $k_{4}^{\prime}$ as well as $[\mathrm{AO}]_{0}$ and $[\mathrm{PANH}]_{0}$. Of course, the three rate constants (Table 2 ) are composite rate constants that also depend linearly on the radical concentration, [ $\left.\mathrm{R}^{\bullet}\right]$, and the presence of other oxidizers. Nevertheless, using fluorescence-time profiles at $150^{\circ} \mathrm{C}$, $195^{\circ} \mathrm{C}$, and $215^{\circ} \mathrm{C}$ and the associated rate constants one can obtain activation energies and even estimates for pre-exponential factors using simple Arrhenius graphs (Fig. 11).

It is insightful to compare the rate constants for reactions (R1) and (R3) obtained by oxidizing jet turbine oil to those associated with oxidation of PANH mixtures in silicone oil. By comparing $k_{1}^{\prime}$ in Tables 2 and 3 one sees that PANH in silicone oil degrades about 6-times to 10-times more slowly, compared to PANH in polyol ester oil. This may be due to the reaction of PANH with organic radicals $\left[\mathrm{R}^{\bullet}\right]$ that can form in polyol ester oil but not in silicone oil. In both lubricants direct reaction of oxygen with PANH is important, but only in silicone oil is this direct reaction the exclusive degradation reaction. The mass spectrum shows that

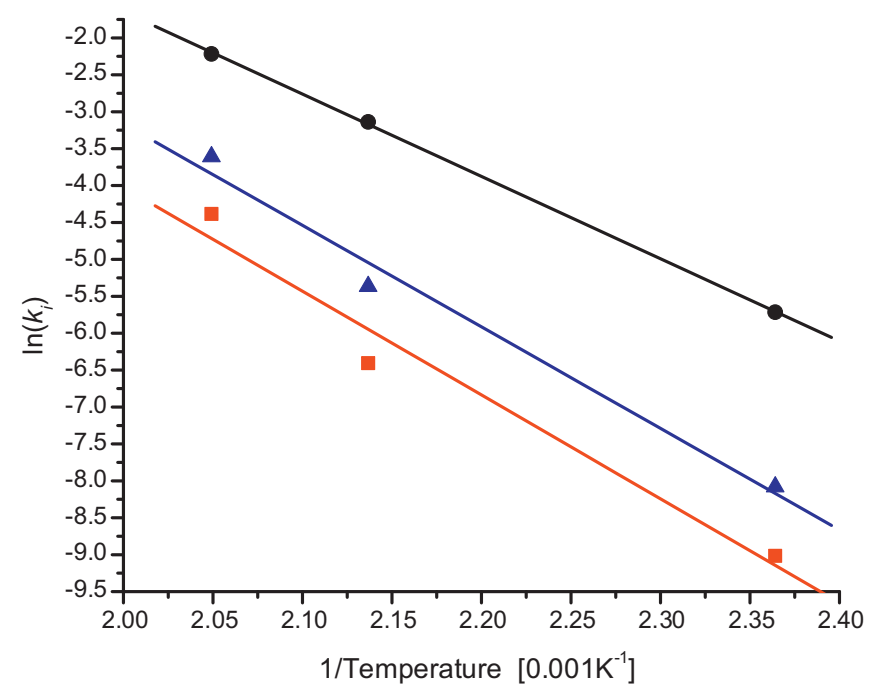

Fig. 11. Arrhenius plot to determine the activation energies listed in Table 2 . The rate constants are composite rate constants that also depend on the concentration of organic radicals and oxygen. (black circles: $k_{1}^{\prime}$; blue triangles: $k_{3}^{\prime}$; and red squares: $\left.k_{4}^{\prime}\right)$.(For interpretation of the references to color in this figure legend, the reader is referred to the web version of this article.) 
Table 3

Rate constants of the formation of $\mathrm{PAN}_{2}$ and the decay of $\mathrm{PANH}$, and $\mathrm{PAN}_{2}$ in PANH-silicone oil mixtures obtained by fitting rate Eqs. (6) and (7) to the data in Fig.9. The two values of [PANH $]_{0}$ are obtained from two separate fits to Eqs. (6) and (7).

\begin{tabular}{ll}
\hline$T(\mathrm{~K})$ & 468 \\
\hline$[\mathrm{PANH}]_{0}$ & $3581 / 8762$ \\
$k_{1}^{\prime}\left(\mathrm{min}^{-1}\right)$ & $0.000521 / 0.000358$ \\
$k_{3}^{\prime}$ & 0.0000328 \\
\hline
\end{tabular}

$\mathrm{PAN}_{2}$ is formed in silicone oil and, given the similarity of the EEM component 2 spectra (Fig. 4) one may assume that $\mathrm{PAN}_{2}$ is also the intermediate product in the oxidation reaction in jet turbine oil. In both oils $\mathrm{PAN}_{2}$ decays, but, again, the decomposition reaction in silicone oil is about 10-times slower than the respective reaction in polyol ester oil. As for PANH, the higher decay rate of $\mathrm{PAN}_{2}$ in jet turbine lubricant is likely due to the much higher concentration of organic radicals in this polyol ester oil.

The kinetic model relies on the steady state assumption for organic radicals and involves effective reaction rates. As soon as $\mathrm{PANH}, \mathrm{PAN}_{2}$ and $\mathrm{AO}$ are all depleted one expects that the model breaks down and the concentration in organic radicals rises. At this point the slower reactions forming aldehydes, ketones and organic acids proceed and the base stock of the oil breaks down. It is therefore not surprising that the depletion of the antioxidants coincides with the sudden onset of the formation of volatile acids as can be seen in Fig. 6.

In Fig. 10 we correlated the breakdown number to the score of component 3, i.e. the fluorescence contribution of the antioxidant AO. Given the calculated activation energy (Table 2), we can now quantify the relative concentration of this component as a function of temperature and time. The half life of AO can be calculated with the pre-exponential factor $A=3 \times 10^{10} \mathrm{~min}^{-1}$ and activation energy $E_{a}=116 \mathrm{~kJ} \mathrm{~mol}^{-1}$ from the linear fit in Fig. 11 .

$t_{1 / 2}(\min )=\frac{\ln 2}{A \exp \left(-E_{a} / R T\right)}=2.4 \times 10^{-11} \exp \left(\frac{14,000 \mathrm{~K}^{-1}}{T(\mathrm{~K})}\right)$

Finally, we can use the empirical correlation of the oil breakdown number (BDN) to the fluorescence PARAFAC score of the antioxidant AO to determine the breakdown number (see Fig. 10). For this particular oil we found the relation

$\mathrm{BDN}=123 \times$ score $^{-0.3}$

At half life, $t_{1 / 2}$, the PARAFAC score of AO is reduced to one-half and the BDN is then increased by a factor $1.23=0.5^{-0.3}$.

\section{Conclusions}

The fluorescence of the particular synthetic lubricant in this study (NYCO jet turbine oil) is dominated by the contributions of two antioxidants and can be easily and robustly quantified using a fiber optic probe. The antioxidant concentration is directly related to the oxidative stability of the lubricant and as the antioxidants are depleted the base stock lubricant rapidly degrades.

It may appear coincidental that the fluorescence of the lubricant happens to be so strongly correlated to the chemical constituents that are also responsible for the oxidative stability. On the other hand antioxidant additives typically consist of conjugated aromatic systems. While the conjugation promotes donation of a hydrogen atom and helps stabilize the intermediate radical, it is also associated with strong fluorescence emission in the visible region of the spectrum. Other antioxidants such as dioctyldiphenylamine and even metal-ligand systems that are added to some lubricants may show very similar behaviour. It also is remarkable that most synthetic base stock is not fluorescent in the near-UV/Vis region such as the polyol ester stock and the silicone oil used in this study. Lubricants with low lying excited states and/or a high degree of unsaturation are likely susceptible to oxidation and even polymerization. We therefore speculate that the results of our study can be transferred to other lubricant systems with different synthetic base stock and different antioxidant or anti-wear additives.

\section{Acknowledgments}

The authors thank Jack Barnes, Klaus Bescherer and Kazem Ghozati for technical assistance. GasTOPS Ltd. (Ottawa) and the Natural Sciences and Engineering Research Council (NSERC) of Canada are gratefully acknowledged for funding. HPL and HO also thank Cathleen M. Crudden (Queen's University) for allowing the use of her laboratory facilities.

\section{References}

[1] R.M. Mortier, M.F. Fox, S.T. Orszulik, Chemistry and Technology of Lubricants, Springer, 2010.

[2] ASTM Vol. D664-11a, ASTM International, West Conshohocken, PA. (2011)

[3] L.A.Toms, A.M. Toms, Machinery Oil Analysis: Methods, Automation \& Benefits, Society of Tribologists \& Lubrication Engineers, Park Ridge, IL, 2008.

[4] ASTM, Vol. E2412-04, ASTM International, West Conshohocken (2004).

[5] ASTM, Vol. D4636-09, ASTM International, West Conshohocken (2009).

[6] ASTM, Vol. D3241-13, ASTM International, West Conshohocken (2013).

[7] ASTM, Vol. D525-12a, ASTM International, West Conshohocken (2012).

[8] Institution B.S., Vol. EN 14112:2003, British Standards Institution, West Conshohocken, PA, 2003.

[9] L.R. Rudnick, Synthetics, Mineral Oils, and Bio-based Lubricants Chemistry and Technology, CRC Press, Taylor \& Francis Group, Boca Raton, FL, 2013.

[10] H. Omrani, J.A. Barnes, A.E. Dudelzak, H.-P. Loock, H. Waechter, Analyst 137 (2012) 8.

[11] P. Kukura, M. Celebrano, A. Renn, V. Sandoghdar, Journal of Physical Chemistry Letters 1 (2010) 3323

[12] M. Celebrano, P. Kukura, A. Renn, V. Sandoghdar, Nature Photonics 5 (2011) 95.

[13] A.A. Boghossian, J.Q. Zhang, F.T. Le Floch-Yin, Z.W. Ulissi, P. Bojo, J.H. Han, J.H. Kim, J.R. Arkalgud, N.F. Reuel, R.D. Braatz, M.S. Strano, Journal of Chemical Physics 135 (2011).

[14] D. Airado-Rodriguez, T. Galeano-Diaz, I. Duran-Meras, J.P. Wold, Journal of Agricultural and Food Chemistry 57 (2009) 1711

[15] J. Tóthová, J. Sádecká, P. Májek, Czech Journal of Food Science 27 (2009) 425.

[16] E. Sikorska, A. Romaniuk, I.V. Khmelinskii, R. Herance, J.L. Bourdelande, M. Sokorski, J. Koziol, Journal of Fluorescence 14 (2004) 25.

[17] D. Patra, A.K. Mishra, Analytica Chimica Acta 454 (2002) 209

[18] O. Divya, A.K. Mishra, Analytica Chimica Acta 592 (2007) 82.

[19] D. Patra, A.K. Mishra, Applied Spectroscopy 55 (2001) 338.

[20] D. Patra, Sensors and Actuators B-Chemical 129 (2008) 632.

[21] A. Andrade-Eiroa, M. Canle, V. Cerda, Applied Spectroscopy Reviews 48 (2013) 77.

[22] A. Andrade-Eiroa, M. Canle, V. Cerda, Applied Spectroscopy Reviews 48 (2013) 1.

[23] D. Patra, Applied Spectroscopy Reviews 38 (2003) 155

[24] R. Mortier, M. Fox, S.T. Orszulik, Chemistry and Technology of Lubricants, Springer, Berlin Heidelberg, 2010.

[25] J. Denis, J. Brian, J.C. Hipeaux, Lubricant Properties, Analysis and Testing, Editions Technip, Paris, 2000

[26] K.S. Booksh, B.R. Kowalski, Analytical Chemistry 66 (1994) A782.

[27] R. Bro, Chemometrics and Intelligent Laboratory Systems 38 (1997) 22.

[28] Multivariate Data Analysis refers to any statistical technique used to analyze data that arises from more than one variable-such as fluorescence EEM spectra. Multiway analysis is a branch of multivariate statistics that extends the standard methods for two-way data, such as component analysis, or factor analysis to multiway data, i.e. data that has an even higher dimensionality.

[29] R. Bro, Critical Reviews in Analytical Chemistry 36 (2006) 279.

[30] A. Smilde, R. Bro, P. Geladi, Multi-Way Analysis with Applications in the Chemical Sciences, John Wiley \& Sons, Ltd., Hoboken, NJ, 2004.

[31] C.A. Stedmon, S. Markager, R. Bro, Marine Chemistry 82 (2003) 239.

[32] C.A. Andersson, R. Bro, Chemometrics and Intelligent Laboratory Systems 52 (2000) 5 .

[33] C.A. Stedmon, R. Bro, Limnology and Oceanography-Methods 6 (2008) 572.

[34] D. Munzke, J. Saunders, H. Omrani, O. Reich, H.-P. Loock, Applied Optics 51 (2012) 9.

[35] R. Bro, H.A.L. Kiers, Journal of Chemometrics 17 (2003) 274

[36] G.E. Totten, Fuels and Lubricants Handbook: Technology, Properties, Performance, and Testing, ASTM International, West Conshohocken, PA, 2003.

[37] N.-Y. Liu, P. He, S.-L. Dong, Comparative Biochemistry and Physiology Part B: Biochemistry and Molecular Biology 161 (2012) 295.

[38] L.F. Cho, Other Information: Ph.D. Thesis, 1982, pp. 246, p. Medium: X; Size. 
Hengameh Omrani is a graduate student (Ph.D. program) at Queen's University and a Research Scientist at GasTOPS Ltd. She obtained her undergraduate degree in Chemistry from the University of Tabriz, Iran (1999) and a M.Sc. degree in physical chemistry from the Shahid Bahonar University of Kerman in 2002. She joined GasTOPS Ltd in 2006 and has since been involved in the development of sensors and systems to monitor the quality of lubricants and fuel. She enrolled in graduate studies at Queen's in 2009 to pursue the development of optical sensor technology for this purpose.

Alexander E. Dudelzak joined GasTOPS Ltd as Director of Research in 2009 after 20 years of being Senior Scientist at the Canadian Space Agency. He is Adjunct Professor, Dept. of Chemistry, Queen's University and has a PhD degree in Physics and Mathematics from the Estonian Academy of Sciences, in Tallinn, Estonia. He was a Senior Scientist/Professor Degree in Optics \& Spectroscopy at the USSR Academy of Sciences, Moscow, Russia. Research interests/area of R\&D involvement include laser spectroscopy; analytical remote and in-situ sensing; radiation interactions with atoms, molecules, crystals, and biological cells; development of measurement systems as payloads for space and terrestrial platforms.
Bruce P. Hollebone is a chemist at the Oil Research Laboratory, part of the Emergencies Science and Technology Section of Environment Canada. His research interests include: the fate and behaviour of oil and petroleum products in the environment; developing new methods for spills studies; environmental forensics for oil spill suspect-source identification; and development and assessment of environmental emergencies response technologies. He obtained his Ph.D. from the University of British Columbia in 1994 and a B.Sc in Chemistry and Physics from McMaster University in 1989.

Hans-Peter Loock is a Professor is the Department of Chemistry at Queen's University. His research interests are in the development of instrumentation for analytical spectroscopy, and in laser photochemistry. He obtained his undergraduate degree (Dipl.-Ing.) at the Technical University of Darmstadt, Germany, and completed his doctoral work at the University of Victoria, Canada. After two years of postdoctoral work at the National Research Council of Canada he joined Queen's University in 1999, where he has since worked on molecular physics and laser photochemistry. Work on fiber-optic detectors includes the development of new absorption detectors and refractive index sensors as well as fluorescence, photoacoustic and mechanical probes. 